\title{
Modelling and verification of bridge behaviour
}

\author{
Jan Bujnak ${ }^{1, *}$, Petra Bujnakova ${ }^{1}$, and Bronisław Jedraszak ${ }^{2}$ \\ ${ }^{1}$ University of Žilina, Faculty of Civil Engineering, Univerzitná 1, 01026 Žilina, Slovakia \\ ${ }^{2}$ Opole University of Technology, Faculty of Civil Engineering \& Architecture, Katowicka 48, \\ 45-061 Opole, Poland
}

\begin{abstract}
Obviously several simplifying assumptions are used in a multitude of analytical methods available to structural analysts. Loading tests are habitually necessary, especially in the case of bridge superstructures of unusual conception, with the main purpose to verify calculation model and assumptions of bridge designer as well as suitability of transformation model. To satisfy all required code criteria still more sophisticated analyses are needed. In order to assure the safety under construction of significant bridges, monitoring is also executed to measure and analyse in site data. Also information significant for long term behaviour of structures is being collected. Especially material properties are controlled, rheological effects checked and straining variation recorded. In the paper, quite uncommon bridge superstructures are presented. The computer modelling is discussed and experimental assessment given.
\end{abstract}

\section{Introduction}

During design and analysis process, many simplified technical approaches are routinely used in the application of theories to practice. With the use of modern structural analysis computer programs, the reliable design alternative, providing the most probable response of a bridge structure due to a range of designed loads can be identified. Field measurements should be performed to determine the actual load effect and to verify the applied analytical models. Modelling principles and suggest some guidelines and consideration in finite element based structural analysis are illustrated in the paper on selected bridge structures. Measurements for monitoring structural response, collected data are shown using tests carried out on composite bridge superstructures.

Field measurements of deflections at certain location of spans and eventual vertical settlement of bridge bearings are usually recorded for selected arrangement of testing load. Registered real strains in chosen critical points provide opportunity for checking and comparing stresses to expected values. Applied test load should simulate a traffic situation, which produce deformation and internal forces large enough to satisfy given criteria of relevant codes [1]. Generally, an efficiency factor $\eta$ is specified. It is expressed as a ration between experimental values $S_{e}$ of any observed parameter produced by test loading and calculated values $S_{c a l}$ developed by code ideal load model. In the case of a road highway bridge, the test loading consists of an appropriate arrangement of heavy vehicles of controlled

\footnotetext{
*Corresponding author: jan.bujnak@fstav.uniza.sk
} 
weight. Efficiency ratio $\eta$ should be between 0.80 and 1.05 , not less than 0.50 , for every recorded experimental value for which a certain type of vehicle arrangement was defined. In the case of a railway bridge, test loading is represented by a set of chosen train engines, eventually in combination with heavy railway cranes. A level of residual part of deflection $S_{r}$ produced by irreversible deformation of members and connections is the supplementary important criterion. This remaining deformation has to be fewer than $10 \%$ of total measured values, i.e. $S_{r} / S_{t o t} \leq 0.10$. The total measured values are given by the amount $S_{t o t}=S_{e}+S_{r}$. The following examples are intended to show how even problems of similar character might be dealt with by essentially different designs.

\section{Steel-concrete composite girder bridge}

\subsection{Structural concept}

Composite steel bridge [2] was especially preferable to normal prestressed concrete structural system, as a compromise between protections of the landscape and transport necessities. Roadway deck is supported on two girders and slim, rather high piers. Because of an angular crossover and arch curvatures of side road approaches as shown in Figure 1a, theoretical spans of main girders are $69.0+81.0+87.0+75.0+63.0+45.0 \mathrm{~m}$. The roadway has a width of $11.5 \mathrm{~m}$ between barriers and the total deck width varies from 14.11 to 16.61 meters. Thus, this composite superstructure defines two-lane overcrossing over its whole 422.0 metres length. Figure $1 \mathrm{~b}$ is showing the bridge layout consisting of the concrete slab and only two built-up plate girder of I-section axially $6.7 \mathrm{~m}$ spaced.

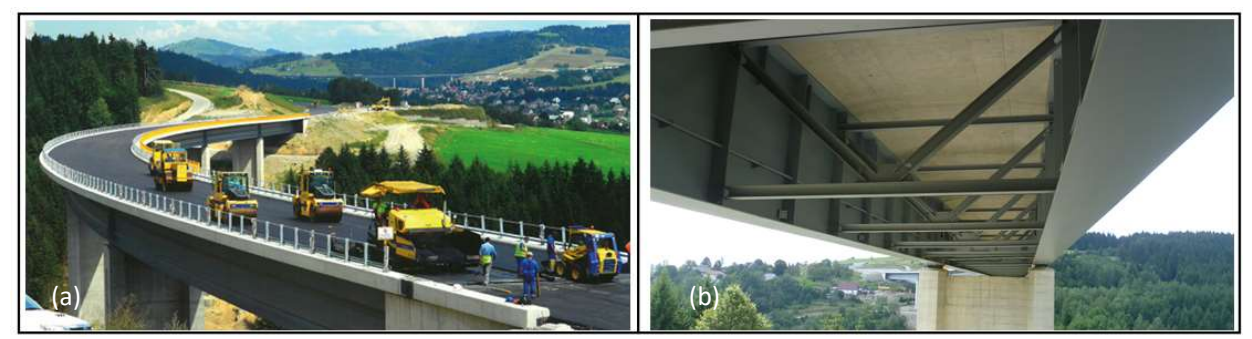

Fig. 1. Bridge structure during erection (a), main girders and cross bracing (b).

The steel plate main composite girders were selected for the bridge having the constant depth of the slender web $4.94 \mathrm{~m}$. Three longitudinal angle stiffeners welded to outer sides of the webs were placed for meeting slenderness requirements and allowing developing shear capacity as well as bending resistance by preventing local buckling. The inconstant area of flanges was used to save material where the bending moment would be smaller or larger in a span. Especially, the top flanges that act with the concrete slab are of the constant $900 \mathrm{~mm}$ width and proportioned by varying thickness from 25 to $40 \mathrm{~mm}$. For increasing the flexural strength of cross-sections, the bottom flanges are $1200 \mathrm{~mm}$ width, and vary in the thickness from 30 to $55 \mathrm{~mm}$. Low-alloy structural carbon steels S355 and S420 as well as S460 have been used for steel bridge structural parts. Truss cross-frames consisting of horizontal chords and diagonals made of HEB sections provide the lateral stability of the plate-girders and help to distribute the vertical loads. End cross frames and diaphragms at piers and abutment are provided to transmit lateral loads to the bearing. Reinforced concrete with 28-days compressive strength C 35/45 was used in slab $250 \mathrm{~mm}$ thick with haunches increasing at $450 \mathrm{~mm}$ above the girders. Shear stud connectors $\varnothing 19 / 150$ from steel grade S235J2 at the interface between the concrete slab and structural steel should ensure a full composite action. 
Solid wall piers of oblong section, both slender and aesthetically appealing provide vertical supports for spans at intermediate points. The seat-type abutments were constructed separately from the bridge superstructure as the reinforced earth-retaining structure using multiple-layer strips from no degradable fabrics to reinforce the fill material in the lateral direction. The face panels as slabs anchored by the strips are subjected to lateral soil pressure. The bridge superstructure seats on the abutment stems through pot bearings comprising plain elastomeric disks confined in shallow steel rings. Teflon sliding surfaces of expansion bearings can accommodate translational movement. Keeper plates are used to retain the superstructure moving in presumed direction. The fixed bearing allowing only rotations but restricting movements is located at the top of the central pier.

\subsection{Transformation model and static testing results}

Curvature and real direction of bearing displacement had to be appropriately implemented into the model represented in Figure 2. The concrete deck and steel main girders were approximated with shell finite elements. Varying thicknesses of elements were adopted for better account of variable deck as well as in fact fifteen different girder sections. Cross truss beams as well as support diaphragms were meshed by member elements, including real eccentricities from bridge slab. Deflections in mid-spans of steel beams and bearing settlement were measured during loading test.

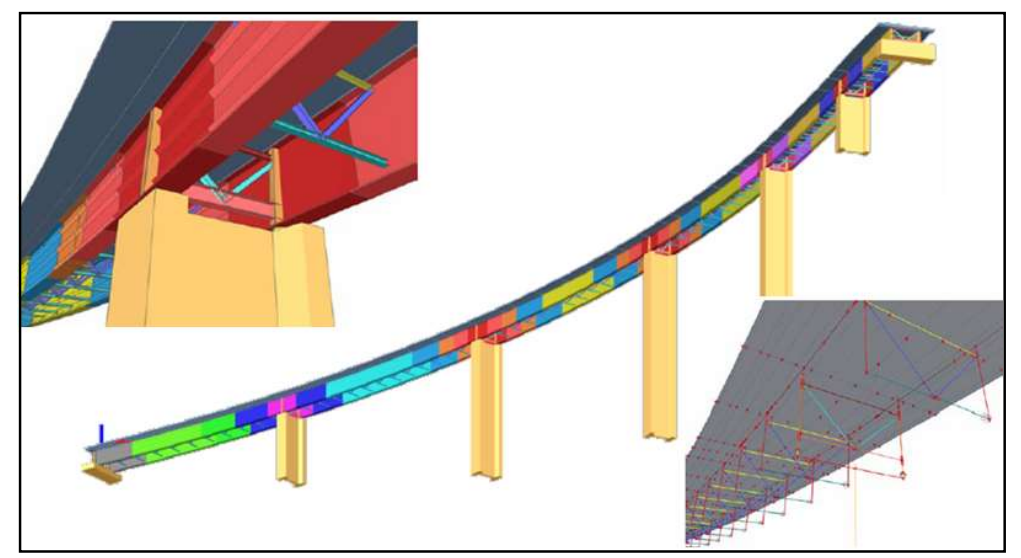

Fig. 2. Bridge finite element modelling.

Applied test load should simulate a traffic situation, which produce deformation and internal forces large enough to satisfy given criteria of relevant codes, e.g. STN 736209 [1]. The efficiency factor as relation $\eta$ between experimental deflection $S_{e}=26.0 \mathrm{~mm}$ produced by test loading and calculated values $S_{\text {cal }}=24.6 \mathrm{~mm}$ in the middle of the fifth span developed by code ideal load model LMI according to EN 1991-2 [3], in the case of this bridge structure, $\eta=0.84$ imposed eight trucks, having the total weight of 42.0 tons each. A level of residual part of deflection $S_{r}$ produced by irreversible deformation of members and connections is the supplementary important criterion. This remaining deformation has to be fewer than $10 \%$ of total measured values. $S_{r} / S_{\text {tot }}<0.10$. This additional condition was also satisfied, since extreme ration $S_{r} / S_{\text {tot }}=0.086<0.10$. This static testing has approved sufficient conformity of the reassured behaviour of the structure with the design calculations.

\subsection{Dynamic load testing}


The bridge was tested also dynamically through passages of two fully loaded four-axle trucks, with a normal axle spacing of $4.5 \mathrm{~m}$. The gross weight of the vehicle rested near the allowed limit of 42 tons as the maximum legal gross weight of vehicle. The test vehicles were driven at constant speed, along the longitudinal bridge axis and always in the same direction. The tests are begun with a vehicle speed of $5 \mathrm{~km} / \mathrm{h}$, which was then increased after every passage in steps of 5 to $10 \mathrm{~km} / \mathrm{h}$ up to the maximum speed $50 \mathrm{~km} / \mathrm{h}$. Tests on the undisturbed pavement were repeated with a plank placed on the roadway in the main measurement cross section. The plank was approximately $60 \mathrm{~mm}$ thick and $500 \mathrm{~mm}$ wide. Produced strains were measured at the mid-point of the second and third spans, as the bridge main characteristic measurement cross sections. The mechanical vibrations were recorded by two accelerators. The strain time dependent variations, transformed at electrical signals were registered by measurement accuracy apparatus Spider, controlled by a notebook.

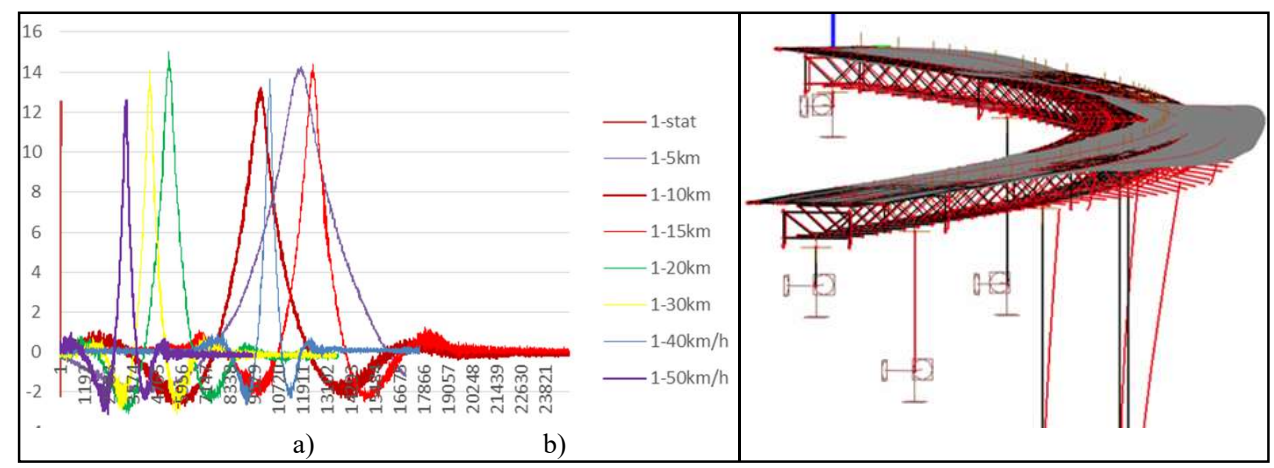

Fig. 3. Strains of the midpoint of the third $87 \mathrm{~m}$ long span under the passage of two 42,0 tons vehicles traveling from $5 \mathrm{~km} / \mathrm{h}$ to $50 \mathrm{~km} / \mathrm{h}$ on the undisturbed pavement (a), second fundamental mode of bending and torsional oscillation (b).

From the registered dynamic signals showed as exemple in Figure 3a, the fundamental frequency ${ }^{\text {obs }} f_{(2)}=1,05 \mathrm{~Hz}$, very close to theoretical value ${ }^{\text {theo }} f_{(2)}=1,03 \mathrm{~Hz}$ was obtained for the second proper mode of the loaded bridge oscillations, as illustrated in Figure $3 \mathrm{~b}$. Then logarithmic damping decrement, which required measurement of the magnitude of the first $S_{f u n d}$ and last strain amplitudes $S_{i}$ having the sane phase, could be identified. Considering the number of periods $i$, the damping was determined from $v=\ln \left(S_{f u n d} / S_{i}\right) / i$, and going from 0,052 to 0,064 . From the peak value $S_{\max }$ of the bridge response during passages of the test vehicles and strain observed under static loading with the same vehicles $S_{\text {stat }}$ at Figure $3 \mathrm{a}$, the dynamic increment can be found, as $\phi=S_{\max } / S_{\text {stat. }}$. Finally the bridge critical velocity $c=26$ $\mathrm{km} / \mathrm{h}$ was identified as corresponding to the maximum dynamic increment $\phi_{\max }=1.15$.

\section{Cable-stayed foot bridge}

\subsection{Structural layout}

A fan-type arrangement of cable $50 \mathrm{~mm}$ in diameter of this footbridge, having two equal end spans of length $37.8 \mathrm{~m}$ and one mid-span of $94.5 \mathrm{~m}$ may offer an attractive and clean appearance, even though a double-plane cable system [4]. The cable slopes are slightly steeper and consequently can provide stiffer supports. The axial force in the girder, which is an accumulation of all horizontal components of cable forces, is smaller. For the freestanding towers $17.94 \mathrm{~m}$ high as mainly compression members, encased steel-concrete 
columns of elliptical cross-section with $1.6 \mathrm{~m}$ in main diameter were the optimal choice. The lock-coil strand system could meet the more strict requirements and offer good workability and economy. The dead-ended concept for cable anchorages at the upper part of towers was designed as simple and economical system. To avoid creating torsional moment in the tower columns, the cables from the main span and the back side span have been attached in the same plane. At the other extremities, the cables are connected to the girder from both girder sides by shop-fabricated steel tubular anchoring members (Figure $4 \mathrm{a}$ ).

This cable-stay footbridge $180.31 \mathrm{~m}$ long with two planes of cables has the orthotropic welded steel-deck, as it can be seen in Figure 4b. The $200 \mathrm{~mm}$ high closed-ribs laminated from $6 \mathrm{~mm}$ thin sheet are parallel to the main span and connected by welding to transverse $400 \mathrm{~mm}$ high floor beams, located at distances $3.15 \mathrm{~m}$. Two main plate girders axially $4.0 \mathrm{~m}$ spaced have the slender web $10 \mathrm{~mm}$ thick and even construction depth of $1.14 \mathrm{~m}$. The flanges are of the constant $300 \mathrm{~mm}$ width and proportioned by varying thickness from 20 to $30 \mathrm{~mm}$. Since the deck plate $10 \mathrm{~mm}$ thick is welded to every component, it should act as the top flange for the ribs, the transverse floor beam, and as a portion of the longitudinal plate girders.

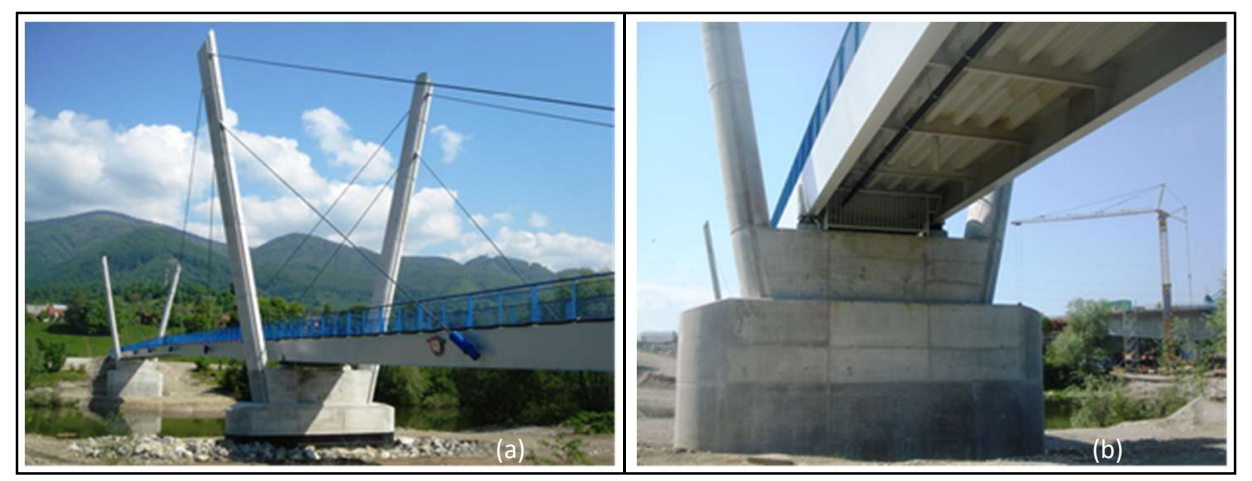

Fig. 4. Concept of tree spans cable-stayed footbridge (a) and components of orthotropic deck (b).

\subsection{Static and dynamic testing}

Figure 5a illustrates the advanced transformation model using software based on finite element procedure. The plate finite elements were used for approximation of the crosssection and orthotropic deck in order to represent appropriately especially bending behaviour and stiffness of the footbridge girder. The real variation of the webs and flanges thicknesses in cross sections along the spans was taken into account. All others members of the deck girder were modelled by one-dimensional member finite elements. The pylons and the piers underneath the main girder were simulated by the member elements with a non-uniform cross-section. The cables were introduced into the model as nonlinear members by their real section areas, material parameters and with initial prestressing forces introduced into the cables.

Uniformly distributed live load of $5.0 \mathrm{kN} . \mathrm{m}^{-2}$ and alternatively special emergency 12 tons heavy vehicle were considered in design of this bridge superstructure. Testing load consisted of four trucks, each of them 13 tons in weight. The deflection produced by this load in the middle cross section of the longest span was $146.1 \mathrm{~mm}$ and the corresponding ratio $\eta=0.60$. However, the most efficient load situation was for the testing load configuration located at the second inner cable anchorage section. The mid-span deflection slightly drooped at 144.9 $\mathrm{mm}$, but the efficiency ratio of this load case went up $\eta=0.65$. 


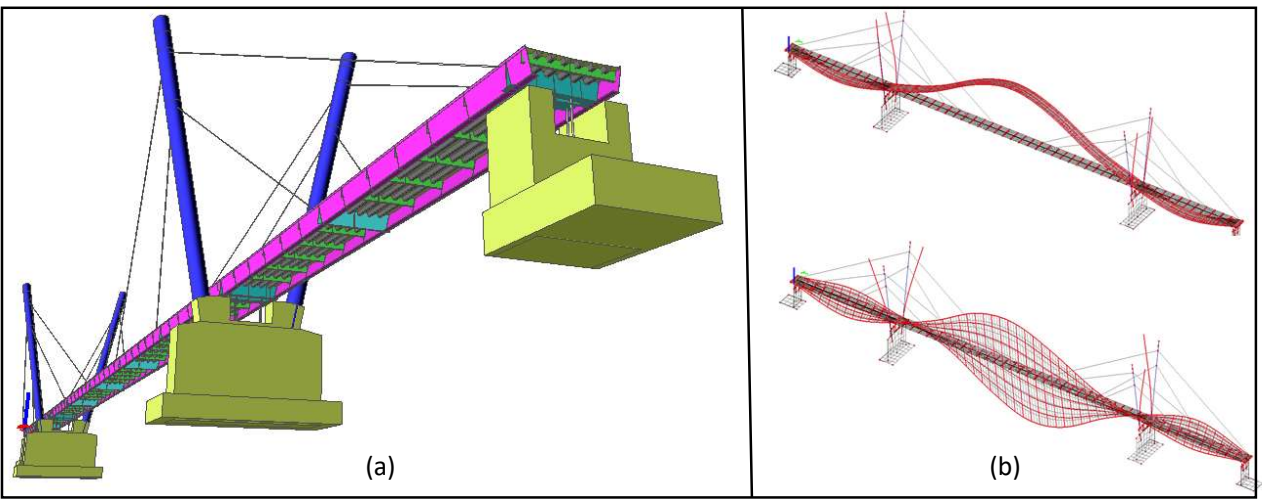

Fig. 5. Numerical model of footbridge (a) and the shapes of the first natural frequencies (b).

Using of the developed model, dynamic analysis was executed, too. Modes of natural vibration and corresponding frequency values were determined. As example, the first bending and torsional shapes of the structure are shown in Figure 5b. Field measurements of dynamic characteristics were taken using the 2.4 tons weighing truck. For each truck passage through the footbridge with different speeds up to $30 \mathrm{~km} / \mathrm{h}$, the dynamic response was monitored by recording strain data. A standard procedure was used to filter and process collected data. The detail analysis of time dependent recorded deflections revealed that for useful values of load speed, bridge structure would oscillate in its first natural proper shape with frequency ${ }^{\mathrm{obs}} f_{l}=1.23 \mathrm{~Hz}$, close to calculated theoretical value theo $f_{l}=1.25 \mathrm{~Hz}$. The torsional oscillation would be also in the first natural shape with frequency $f_{1}=2.06 \mathrm{~Hz}$. The value of the damping decrement factor between 0.024 and 0.043 was also derived from measured data. As a conclusion the identified dynamic characteristics have typical values for this type of bridge superstructure.

\section{Truss railway bridge}

\subsection{Structural Components}

The one-span railway bridge has been rebuilt on existing route to the deck bridge with its floor connected to the upper chords of the main truss girders of Pratt form at Figure 6a, having spans of length $38.4 \mathrm{~m} \mathrm{[5].} \mathrm{Due} \mathrm{to} \mathrm{restrictive} \mathrm{clearances} \mathrm{and} \mathrm{inadequate} \mathrm{carrying} \mathrm{capacity,} \mathrm{its}$ rehabilitation could not be economically justified. The low-maintenance renewed superstructure has only two main truss $4.5 \mathrm{~m}$ high and axially $3.4 \mathrm{~m}$ spaced. The bridge with open deck meets clearance space required for passage of contemporary rail traffic. The truss members are the double plane type. The top chords have built-up box section $400 \mathrm{~mm}$ high with basic web plate thickness $20 \mathrm{~mm}$, variable for adapting cross sections to stresses along a span and $350 \mathrm{~mm}$ constant distance apart to facilitate connections of web built-up I shape section, fitting inside the gussets. This distance $350 \mathrm{~mm}$ between web gusset plats remained the same for the trusses, even for bottom chord under tension of inverted U section $400 \mathrm{~mm}$ high.

Open deck have sleepers $0.24 \times 0.24 \mathrm{~m}$, both longer and larger in cross section than at the standard track size, supported directly on stringers and floor beams as load-carrying elements of the structure. At bridge abutments, end posts should transmit concentrated loads to these supports. Cross frames consisting of intermediate posts, lateral bracing struts and floor beams are compatible with their locations to provide lateral stability of top chords. The bracing 
transferring horizontal loads to bearings and providing lateral structural stability in horizontal plan consists of stiff framed grid from deck stringers and floor beams.

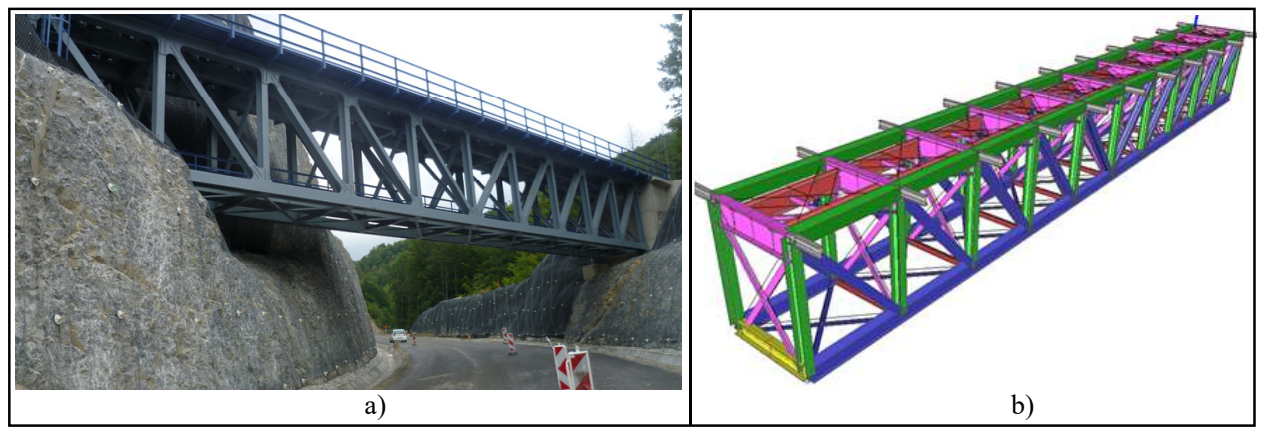

Fig. 6. Truss bridge during construction (a) and its transformation model (b).

Because of the clearance requirements and restrictions of construction, the closed-end abutments at the superstructure edges should provide not only the vertical support to the bridge superstructure at the bridge ends, but also connect the bridge with the approaches and retain the track base materials from the bridge spans. The fixed bearing restricting movements is located at the top of the left abutment. Approach transition slabs connected to the backwall of the relatively high stem abutments have to reduce significantly backfill soil and footing settlements. As bridge carry signal and communication cables, different provisions needed to be made for these additional items. The standard EN 1991-2[3] limit quite rigorously the amount of allowable deflection in track under train passage. Thus, the live load-deflection control was a significant serviceability criterion, governing designs rather than strength.

\subsection{Transformation model and testing results}

The appropriate interaction between the deck and main bridge structure had to be considered carefully in our numerical model. Figure $6 \mathrm{~b}$ shows the developed spatial finite numerical model based on Scia Enginer software programme [7]. Particular attention was paid to the accurateness of the model to obtain relevant real behaviour. Appropriateness of the model was confirmed by a comparison of values produced by numerical analysis and those obtained from measurement. In the loading test, two locomotives of type T419, each 84 tons heavy, were used as live-load in specified configurations. The recorded extreme vertical deflection in mid-span was $f_{\text {test }}=19.5 \mathrm{~mm}$ and corresponding load efficiency relation $\eta=0.52$. The total deflection $f_{c a l}=37.5 \mathrm{~mm}$ due to classified load model 71 standardised in EN 1991-2 [3] did not exceed the allowable limits and the bridge can be considered as sufficiently stiff.

\section{Prestressed concrete bridge}

\subsection{Structural highway bridge arrangement}

The new bridge, composed of two separate concrete beams, is located in the urban area [6]. Both similar structures consist of a total of eighteen continuous spans with lengths $46.10+15$ $\mathrm{x} 60.50+49.80+32.80 \mathrm{~m}$. The shorter end spans adjacent to the abutment had to be built by employing falsework. The rest was constructed using cantilever technology with selflaunching gantry. The roadway has a variable width from 11.75 to $13.25 \mathrm{~m}$ between barriers and the total deck width varying from 14.25 to 15.75 meters. 
Figure 7a shows the typical characteristic cross-section consisting of single-cell box girders of the constant-depth 3.0 meters providing the most efficient section for casting. The web thickness $250 \mathrm{~mm}$ was determined by shear considerations, as tendon ducts internal to the concrete were present. The local haunches are used at the intersection of the bottom slab and the webs to provide sufficient space for accommodating the required number of tendon ducts. The distance $7.5 \mathrm{~m}$ between the webs at their intersection with the top slab was determined by achieving a reasonable balance between the moments and providing the necessary flexural capacity. The top slab thickness resulted from limit deflection criterion under live loading. Since segmental box girder has transversely post-tensioned top slabs, the minimum thickness should be $250 \mathrm{~mm}$, with possibly thicker values at the tendon anchorages. The bottom slab thickness could be less, down to $200 \mathrm{~mm}$, as there is no transverse posttensioning embedded.
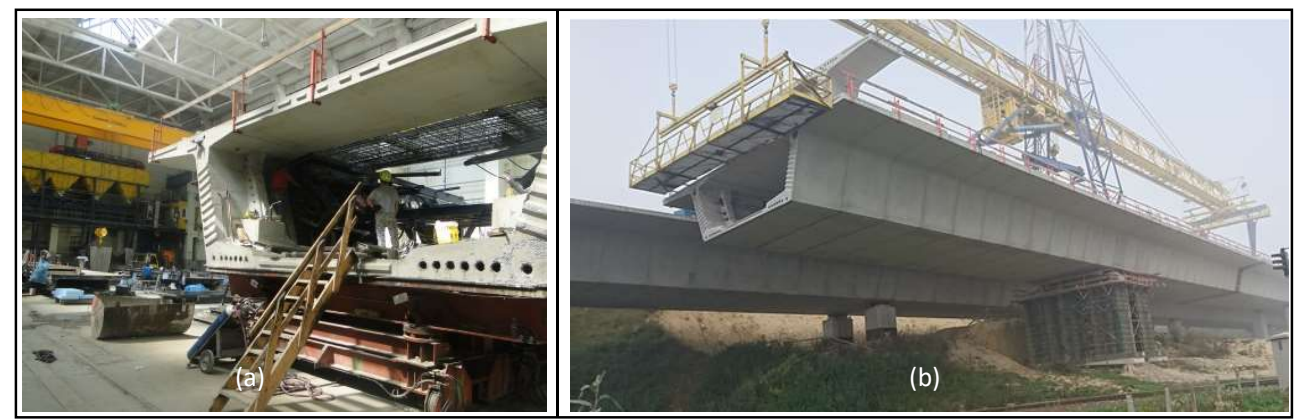

Fig. 7. Segments casting in in adjustable molds (a), self-launching truss gantry (b).

The cantilevers were mostly constructed in $2.2 \mathrm{~m}$ long segments. The size and weight of precast segments 60 tons were limited by the capacity of transportation and placing equipment. The successive segments were cast against the adjoining segment in the correct relative orientation with each other starting from the first segment away from the pier. These precast segments in the casting yard and molds were transported to the specific piers by land, than on the completed viaduct, in the same order, and hence no adjustments were necessary between segments during assembly. The single erection truss with portal legs was used as the lifting equipment, as it can be seen in Figure $7 \mathrm{~b}$. The joints were made of the very thin layer of epoxy resin, which did not alter the match-cast geometry. Posttensioning could proceed usually as early as practicable since there was no need for joints to cure. Tendons were internal to the concrete section housed in pipes. A minimum number of tendons were required for the balanced cantilevering process, anchored on the face of the segments and internal blisters.

\subsection{Superstructures testing}

The compressive strength as the common performance property was measured by breaking cylindrical concrete specimens $150.300 \mathrm{~mm}$ size (Figure 8a) in the laboratory compression - testing machine and calculated from failure load divided by the cross - sectional resisting area. The results from cast cylinders validated existing concrete strength as well as adequacy of curing and protection measures.

The next test method measured the load-induced time-dependent creep strain on moulded concrete sample subjected to sustained longitudinal compressive load (Fig. 8b). Creeping testing machine consists of main unit using disk springs specifically selected to maintain constant load over the range of deformation probable during creep tests and measured using 
externally mounted mechanical gage points. Resulting experimental rheological strain development came close to curves in Figure 8d.

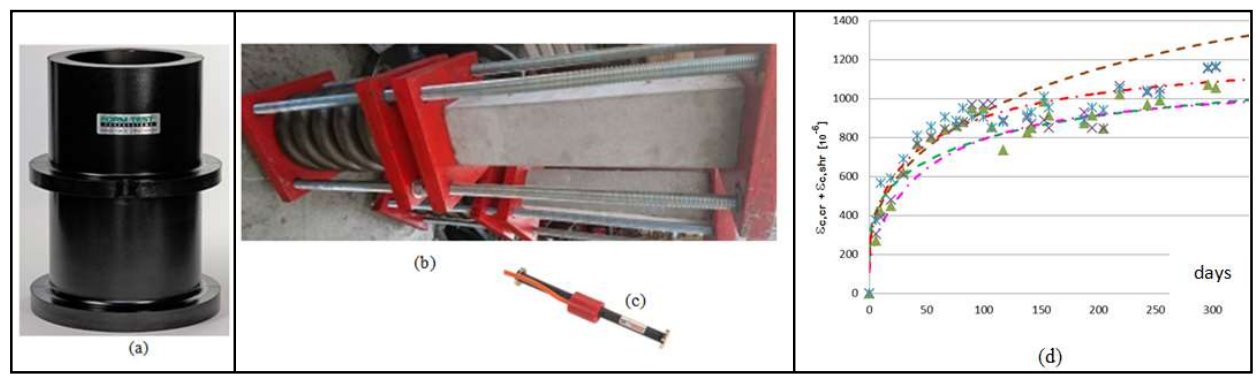

Fig. 8. Concrete strength (a), creep testing (b), wire strain sensor (c), creep and shrinkage in time (d).

Temperature gradients are caused by the top or bottom surface of the structure being warmer than the other. This distribution is nowadays assumed to be nonlinear with magnitudes given in relevant standard EN 1991-2 [3]. Due to its high thermal mass, concrete structures are more adversely affected by the thermal gradient than steel structures. Effects of a linear portion of temperature gradient impose the unrestrained curvature at any point along the span. At that point, the final force distribution can be determined by evaluating the redundant support reactions. Nonlinear constituent of temperature gradients are more difficult to evaluate. The free thermally induced strain is proportional to the temperature distribution. In order for the section to remain plane under the effects of the applied temperature gradient, the self-compensating stress is induced. The final strain distribution on the section is the sum of the free thermally induced strain and the strain induced by the selfcompensating stresses. Similar to the linear gradient, the total stress on a section is, therefore, the summation of the self-compensating stresses and the continuity stresses.

Observations of the bridge data coupled with detail examination could led to the assumptions that appear simplistic but important factors in the design. Firstly it can be concluded that strain changes are linearly proportional to changes in temperature, as the straining variation were found linearly correlated with temperature readings from different parts of the bridge. Also it was observed that the mass of the bridge forced the strain change to delay behind the temperature and the bridge takes some time to warm up and cool. The geographical north-south orientation of the structure with respect to the sun originates that the temperature of the west end of the bridge will have a time-lag behind the temperature of the east end. Given these assumptions, a linear temperature distribution can be chosen in a system analyses.

For strain time dependent variation, the seventh and sixteen mid-spans as well as two neighbouring piers sections were implemented with sensors. The vibrating wire strain gauges according to Figure 8c, suitable for long term readings were placed on the concrete deck and on the girder web. Four strain gauges were placed at the intersection of the slabs and the webs of cross - sections and spaced along the length of each girder. Since there were two girders, a total of 32 strain gauges were placed on both bridges. The histories of strain development were recorded and structural response computed from the measured readings. At the same time, temperature measurements were made on the specified 32 different locations across the centre of the span and pier sections. The data acquisition for each site investigation took about six hours. Figure 9 as an example, illustrates normal stresses variation in the mid-section of the seventh span during construction stages. 


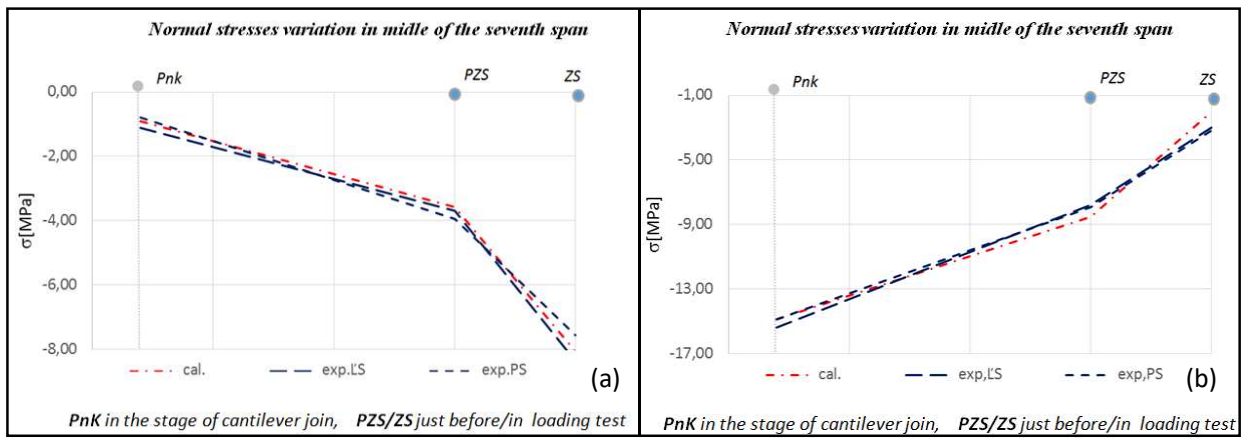

Fig. 9. Normal stresses variation for three construction stages at the top (a) and bottom web sides (b).

\section{Concluding remarks}

The bridge case studies in this paper might illustrate, that loading tests together with analytical modelling represent very powerful control mechanism. Practically, all relevant differences, defects or even static imperfections can be revealed before putting a bridge into exploitation. In addition, experimental data and numerical models present powerful tools for identification of real bridge behaviour, the integrity of the structure evaluation and validation and optimisation of the structural design.

Global stresses and deformations of segmental box-girder bridges due to the effects of dead load and posttensioning as well as the long-term effect of creep can be predicted during the design process by the use of a computer analysis program. But the real values are dependent, to a large extent, on the method of construction of the structure, the age of the segments when post-tensioned, and the time when other loads are applied. Real more correct behaviour, especially of major structures can be identified only by field measurements. The given case studies should illustrate actual possibilities and practise of real structural behaviour verification, especially in bridge engineering area.

\section{References}

1. Slovak Technical Standard - STN 73 6209, Proof load tests of bridge, SUTN Bratislava, (1993)

2. Final Report from Proof Load Test, SO 242 - 00 Bridge on D3 in km 25,140 from Svrčinovec to Polish border, University of Žilina, Slovakia, (2017)

3. EN 1991-2: Eurocode 1: Actions on structures - Part 2: Traffic loads on bridges, European Committee for Standardisation (2003)

4. Final Report from Proof Load Test, SO 206 - 00 Footbridge and special vehicles crossing in Turčianske Kl'ačany, University of Žilina, Slovakia, (2016)

5. Final Report from Proof Load Test of the SO 205-00 Bridge on railway track n. 174 over the road I/72 in km 2,059 Zbojská, University of Žilina, Slovakia, (2015)

6. Monitoring report of the bridge SO 209 at the highway construction D1 Hričovské Podhradie - Lietavská Lúčka. University of Žilina, Slovakia, (2018)

7. J.Bujňák, Steel bridges. Management, maintenance and reconstruction. University of Žilina, (2006) 